\title{
Using Near Infrared for Studying Lemming Subnival Behavior in the High Arctic ${ }^{+}$
}

\author{
Davood Kalhor ${ }^{1, *}$, , Anastasiia Pusenkova ${ }^{2}$, Mathilde Poirier ${ }^{3}$, Gilles Gauthier ${ }^{3}$, \\ Tigran Galstian ${ }^{2}$ and Xavier Maldague ${ }^{1}$ \\ 1 Computer vision and systems laboratory, Department of Electrical and Computer Engineering, Université \\ Laval, Quebec City, QC G1V 0A6, Canada; xavier.maldague@gel.ulaval.ca \\ 2 Center for Optics, Photonics \& Laser, Dept. of Physics, Engineering Physics \& Optics, Université Laval, \\ Quebec City, QC G1V 0A6, Canada; anastasiia.pusenkova.1@ulaval.ca (A.P.); \\ tigran.galstian@phy.ulaval.ca (T.G.) \\ 3 Centre d'études nordiques and Department of Biology, Université Laval, Quebec City, QC G1V 0A6, Canada; \\ mathilde.poirier.1@ulaval.ca (M.P.); gilles.gauthier@bio.ulaval.ca (G.G.) \\ * Correspondence: davood.kalhor.1@ulaval.ca \\ + Presented at the 15th International Workshop on Advanced Infrared Technology and Applications \\ (AITA 2019), Florence, Italy, 17-19 September 2019.
}

Published: 19 September 2019

\begin{abstract}
Despite the crucial role of lemming in the Arctic ecosystem, many aspects of its ecology are still unknown. The main challenge of studying lemming is that this rodent does not hibernate in winter and remains active under snow. To tackle this challenge, this paper presents a monitoring system based on near infrared. Design and implementation of a system that should work autonomously in the harsh arctic environment is really challenging. After developing the first version of the equipment, we installed three units at Bylot Island, Nunavut, Canada. Retrieved videos were promising and showed the great potential of this system in assisting ecologists to study the subnivean ecology of the Arctic. To the best of our knowledge, these are the first ever videos of lemming that have been recorded under snow in winter in the Arctic.
\end{abstract}

Keywords: lemming; monitoring rodents; near infrared camera; subnivean ecology; Arctic ecology

\section{Introduction}

Lemming is a small mammal whose habitat is the Arctic, ranging from large areas of northern Canada to northern Fennoscandia. Despite the crucial role of this animal in the Arctic food chain [1], many aspects of its ecology and behaviors, such as the population fluctuation and winter breeding are poorly known [2].

One of lemming mysteries that has puzzled ecologists for decades (for example see [3-5]) is that its population goes up and down in a cyclic manner. Many ecologists have tried to find a scientific answer to these dramatic variations. Studies on this subject can be categorized into two groups. They have hypothesized that either lemming-predator or food-lemming interactions are the main cause. However, neither of these groups has been able to find any conclusive evidence supporting their hypotheses. For example, Turchin et al. [4] studied the impact of prey-predator interaction for Norwegian lemmings through applying different statistical tests to three datasets of lemmings. But, their finding was against such a hypothesis. Bilodeau et al. [5] studied the behavior of Canadian lemmings on Bylot Island, Nunavut during summer from 2009 to 2012 and wanted to find the reason behind these cyclic population variations. By assuming the truth of the second hypothesis (food-lemming interaction drive), they predicted that a decline in food plants must be seen following a winter grazing. But, their observations showed that these sorts of predictions are not correct and consequently rejected that hypothesis. This result is not consistent with some of previous studies. For instance, according to the study conducted by Moen et al. [6] about 
Norwegian lemmings in northern Fennoscandia, a peak in the lemming population causes a significant decease in snowbed vegetation.

Despite a tremendous amount of research over decades, the puzzle of boom and bust cycles in the lemming population has still remained an unsolved controversial issue [7]. As also suggested by some other researches [2], we believe underlying cause of this failure is the lack of direct studies on the winter breeding and life of lemmings under snow. However, large snow pack, long winter, very low temperature are serious barriers to understand lemming in these remote areas. The good news is that the technological advancements have already opened ways to address this sort of problems, but surprisingly, they have not been employed with two exceptions. Recently, a group of ecologists in Norway [8,9] have made some attempts to utilizing a camera from Reconyx Inc. and reported some photographs of small mammals recorded by their camera trap in northern Norway. Gilles Gauthier and his collaborators [10] made a similar attempt in the Canadian Arctic using a camera from the same manufacture, but they achieved very limited success due to unsatisfactory performance of this camera in presence of permafrost. A major difference between these works is that the environment in Norway is subarctic and there is not permafrost as in the Canadian or Russian Arctic. This is an important difference because the Canadian researchers have to deal with serious frosting issues due to permafrost, which is absent in Norway.

To cope with interdisciplinary nature of this problem, a collaboration of researchers from three disciplines was established. In our first attempt, a monitoring system was developed to observe the lemming behavior under snow. This system utilizes a near infrared (NIR) camera to be able to record videos under total darkness. The system is described in the next section. Then, we report the performance of the system within its first recording season.

\section{Development of Monitoring System}

The proposed system as shown in Figure 1 is made of four units: environment, data acquisition, power management and low-level control system, and power unit. Environment is a trapping box designed to hopefully attract lemmings under snow in winter. Having nest in winter is vital to maintain thermoregulation for newly born and young lemmings. Relying on previous experiences of Gilles Gauthier and his collaborators [10], we could design a new trapping box to make it more efficient. Figure 2a shows the box details. Lemmings can enter the box through pipes $B$ and $C(6 \mathrm{~cm}$ diameters and appropriate for lemming). Hole $\mathrm{A}$ is the position from where the system monitors inside the box.

The system must work under nearly complete darkness for almost the entire recording season. This issue can be addressed in different ways. The most intuitive approach would be to create enough luminance using a visible light source. This approach is not appropriate because of its destructive impact on lemmings and increasing power consumption. An alternative approach is to utilize near infrared camera. In this way, the destructive effect of the light source can be significantly reduced.

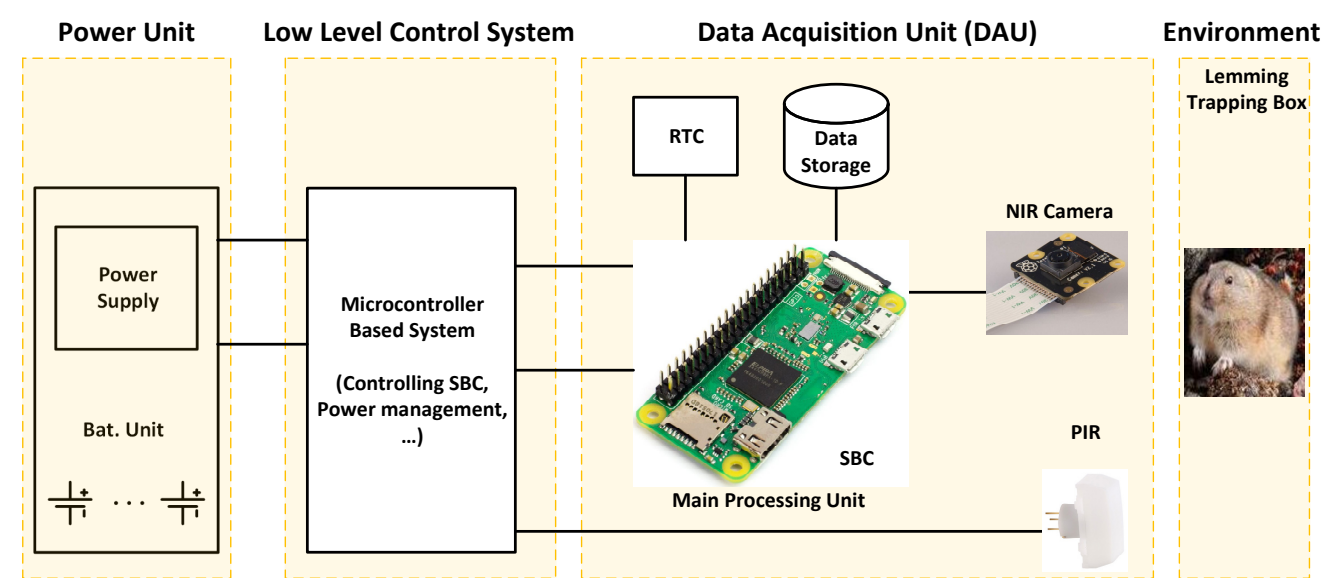

Figure 1. The block diagram of the developed monitoring system. RTC: Real Time Clock. 


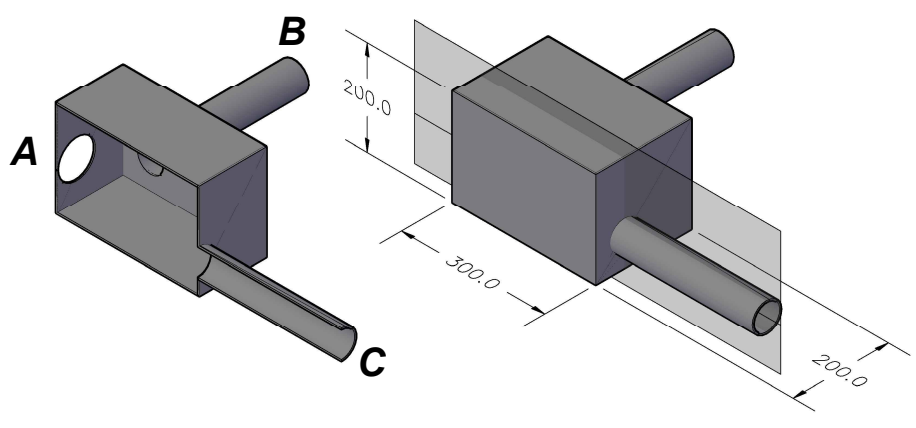

(a)

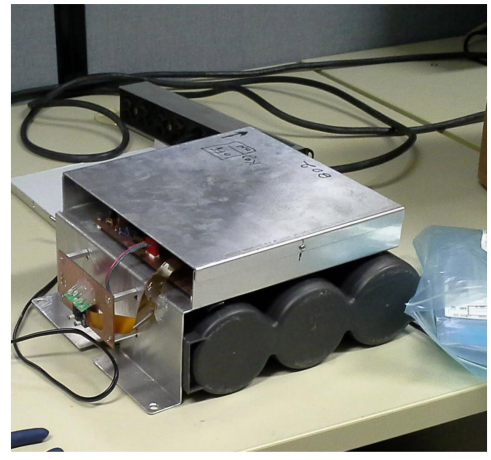

(b)

Figure 2. (a) The lemming trapping box. The left image is the cross section of the box along the light gray plane. A lemming can freely enter the box or leave it via entrances B and C. (b) First prototype of the system.

Full time monitoring is desirable but inaccessible due to shortage of power sources. Therefore, a sample based approach directed by a passive infrared (PIR) motion detection sensors is suggested such that videos will be recorded for limited periods only during the presence of lemmings inside the box. The heart of image acquisition and data storage units is a single based computer (SBC). For this purpose, we used Raspberry Pi. Interaction with other parts of the system, including camera and real time clock is done through low-level programming rather than operation system (e.g., Windows or Linux). A low-level processing unit controls the operation of SBC by monitoring sensory signals, including the motion detection sensors. Recorded videos are stored in a SD memory card.

Discussing the details of this system is beyond this short report. However, it is worth mentioning some of challenges that we had to deal with. Design and implementation of this system involves different aspects of electronics from data acquisition to power management. The ability of the system to cope with very low ambient temperatures and high humidity for an extended period of time, frost formation, and lack of electricity are of critical importance for success. Once the equipment is installed, no intervention will be possible for a whole recording season (around nine months). Consequently, autonomy and robustness are two crucial features for the system. Parts of the first prototype of the system are shown in Figure $2 b$.

\section{Results and Discussion}

Three units of the developed system were prepared and installed at Bylot Island, Nunavut, Canada $\left(73^{\circ} \mathrm{N}, 80^{\circ} \mathrm{W}\right)$ in August 2018. In early June 2019 , we retrieved data from deployed units. A deep investigation of the recorded data is necessary which has not been done yet. However, preliminary checks revealed promising results.

Sign of lemmings presence (faeces and grasses) in all three trapping boxes were observed which shows the effectiveness of the trapping method. Moreover, all three monitoring systems have worked without any failure and recorded 488 videos; sample photos are shown in Figure 3. About 154 videos $(32 \%)$ contained high quality images and were chosen for further analysis. The rest were videos with blur images, bad views, or no lemmings. Our findings will be revealed in future publications.

Our system offers at least three important advantages in comparison with works of the Norwegian research group [8,9]. First, our system records videos while they only reported three images for each recording. This feature provides ecologists with the opportunity of observing lemming over a longer period and hence collecting more useful information. Second, thanks to a better filming view, our videos contain some details that cannot be recorded by their system because of installing the camera on top of the trapping box. The third advantage is that our new box design and camera configuration minimize frost formation on lenses in winter. 




(a)

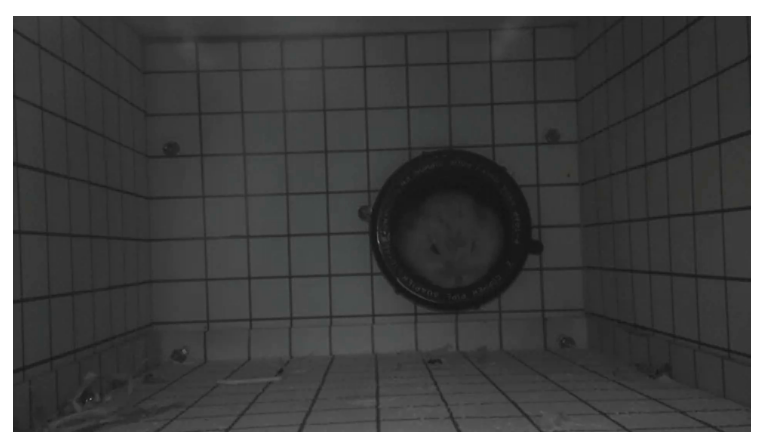

(b)

Figure 3. Two examples of lemming images in the videos taken by the system.

\section{Conclusions}

We presented a near infrared observatory system to study lemming under snow in the arctic winter. Using the new system, for the first time we could successfully record videos of lemming under snow in winter in the Arctic. Moreover, this is the first time an image acquisition equipment has filmed lemming under snow in the Canadian Arctic which is more challenging than the environment in Norway. Although different aspects of our system require improvement, preliminary results showed a very promising future for this wildlife monitoring system and we believe similar attempts will eventually lead to a revolution in the study of subnivean ecology of the Arctic in near future.

Funding: This research was supported by the Sentinel North program of Universite Laval, funded by the Canada First Research Excellence Fund, the Natural Science and Engineering Research Council of Canada, the Network of Center of Excellence ArcticNet, Polar Knowledge Canada and the Polar Continental Shelf Program of Natural Resources Canada.

\section{References}

1. Legagneux, P.; Gauthier, G.; Lecomte, N.; Schmidt, N.M.; Reid, D.; Cadieux, M.c.C.; Berteaux, D.; Bety, J.; Krebs, C.; Ims, R.; et al. Arctic ecosystem structure and functioning shaped by climate and herbivore body size. Nat. Clim. Chang. 2014, 4, 379.

2. Krebs, C.J. Of lemmings and snowshoe hares: The ecology of northern Canada. Proc. R. Soc. B Biol. Sci. 2010, 278, 481-489.

3. Elton, C.S. Periodic Fluctuations in the Numbers of Animals: Their Causes and Effects. J. Exp. Biol. 1924, 2, 119-163

4. Turchin, P.; Oksanen, L.; Ekerholm, P.; Oksanen, T.; Henttonen, H. Are lemmings prey or predators? Nature 2000, 405, 562.

5. Bilodeau, F.; Gauthier, G.; Fauteux, D.; Berteaux, D. Does lemming winter grazing impact vegetation in the Canadian Arctic? Polar Biol. 2014, 37, 845-857. doi:10.1007/s00300-014-1486-x.

6. Moen, J.; Lundberg, P.A.; Oksanen, L. Lemming grazing on snowbed vegetation during a population peak, northern Norway. Arctic Alpine Res. 1993, 25, 130-135.

7. Fauteux, D.; Gauthier, G.; Berteaux, D. Seasonal demography of a cyclic lemming population in the Canadian Arctic. J. Anim. Ecol. 2015, 84, 1412-1422.

8. Soininen, E.M.; Jensvoll, I.; Killengreen, S.T.; Ims, R.A. Under the snow: A new camera trap opens the white box of subnivean ecology. Remote Sens. Ecol. Conserv. 2015, 1, $29-38$.

9. Building a Sensor System for a Large Scale Arctic Observatory; Open Channel Publishing: Copenhagen , Denmark, 2016.

10. Bilodeau, F.; Kenney, A.J.; Gilbert, B.S.; Hofer, E.; Gauthier, G.; Reid, D.G.; Berteaux, D.; Krebs, C.J. Evaluation of a technique to trap lemmings under the snow. Arctic 2013, 32-36.

(C) 2019 by the authors. Licensee MDPI, Basel, Switzerland. This article is an open access article distributed under the terms and conditions of the Creative Commons Attribution (CC BY) license (http:/ / creativecommons.org/licenses/by/4.0/). 